\title{
Young people's learning trajectories in the digital age
}

\section{Raquel Miño Puigcercós}

rmino@ub.edu

Department of Didactics and Educational Management, University of Barcelona, Spain

\begin{abstract}
The immersion of societies in the digital and networked age has led to an increase of opportunities for young people to learn across countless face-to-face and online contexts. However, youth disaffection towards school remains high and access to opportunities across and within countries is remarkably unequal. This article builds on the results of two ethnographic case studies conducted in Spain and the learning stories narrated by 22 youth about their transitions across home, school, spare time, extracurricular activities, trips and virtual environments. The analysis of the stories show how young people establish connections and feel tensions across their experiences, creating continuities and discontinuities that are key for their learning. It also evidence that secondary school is only one node of the big sociocultural network through which young people learn. Building on the results, the conclusions raise the question: might a better understanding of learning trajectories favor a more inclusive educational system?
\end{abstract}

\section{Keywords}

Youth; learning trajectories; secondary school; ethnography. 


\section{Introduction}

Two of the main questions that have been explored from the fields of Psychology and Pedagogy since its origins have been: what does learning mean and how do individuals learn? When we commonly think about learning, we relate it with change, improvement or development. According to the psychologist Lev Vygotsky, "learning is a social, cognitive, and affective practice that has the potential to pull emerging development forward. Learning is also a unified process of coming to know about the world, others, and oneself; becoming a social individual; and coming to value different ways of thinking, feeling and acting - all of which occurs through relationships" (Vadeboncoeur \& Rahal, 2015, p. 57). Based on this definition, we can say that if we want to study how individuals learn, we also need to understand the world that surrounds them, the society in which they are immersed and the cultural tools they use.

There have been a number of researchers in the last three decades who have been studying the processes of learning and human development from a sociocultural perspective (Barron, 2006; Erstad \& Sefton-Green, 2013; Leander, Phillips \& Headrick, 2010; Vadeboncoeur, KadyRachid \& Moghtader, 2015; Voussoughi \& Gutiérrez, 2014). However, despite the fact that the contributions from the field of Psychology and Pedagogy remain as a theoretical base, it became an interdisciplinary field of research at its intersection with Neuroscience, Philosophy, Anthropology and Sociology. At the same time, this interdisciplinarity has brought methodological richness and complexity, since many methods and perspectives have been incorporated. Some of them are participatory action research (Bland \& Atweh, 2007; Kemmis, McTaggart \& Nixon, 2013), inclusive research (Nind, 2014; Nind, 2017) learning analytics (Bailón, Carballo, Cobo, Magnone, Marconi, Mateu \& Susunday, 2015; Selwyn, 2015), and virtual ethnography (Hernández Hernández, Fendler \& Sancho, 2013; Hine, 2000).

Numerous studies with a sociocultural and interdisciplinary perspective have addressed young people's learning experiences, highlighting that the ways they learn across contexts is an analytical dimension that should be further studied (Barron, 2006; Erstad \& Sefton-Green, 2013; Vadeboncoeur, Kady-Rachid \& Moghatader, 2015). This article is situated in this arena of research, which considers that the opportunities to learn in the $21^{\text {st }}$ century have increased exponentially, impacting the way individuals learn. We learn constantly, everywhere, when we are open to learn and when we least expect it (Thomas \& Brown, 2011). Furthermore, the contexts through which learning is promoted are not only face-to-face, but also virtual. The mobilities of individuals among countries have grown up without precedents in the last years and it is easier to access information and contact people from all around the globe. Because of all these transformations, learning has been described as life-long, life-wide and life-deep (Banks, Au, Ball, Bell, Gordon, Gutiérrez, Brice, Lee, Lee, Mahiri, Suad, Valdés \& Zhou, 2007). It means that individuals learn during their whole life, at any age, in different kinds of contexts and deeply, through multiple activities, resources and environments.

On the obverse side of the coin, while spaces to learn outside formal education are growing up, early school leaving and disaffection rates stay high in many countries. In Spain, $19 \%$ of young people aged 18 to 24 years old abandon the educational system without completing secondary school $^{1}$. It makes Spain one of the countries in the European Union with the higher school dropout rate. This data evidence that stipulating the ages at which young people have to be enrolled in schools is not enough to ensure that they engage in the educational system. Further evidence also shows that early school leaving is related with social inclusion. According to the European

\footnotetext{
${ }^{1}$ Eurostat, 2016. European Commission. European Semester Thematic Factsheet. Early School Leavers. https://ec.europa.eu/info/sites/info/files/file import/european-semester thematic-factsheet early-schoolleavers en.pdf 
Commission (2016), "young people who leave education and training prematurely are bound to lack skills and qualifications, and face a higher risk of unemployment, social exclusion and poverty" (p. 1). Consequently, we are failing to reduce the sociocultural divide and to guarantee that every youth get ready to live, work and cohabit in the contemporary society.

Another aspect that has been addressed during the last years from educational research has been young people's disaffection towards secondary school. Nowadays, many governments are making an effort to transform the educational system to be able to answer to the needs of young people and promote their learning and active participation in society. Taking into consideration David Berliner's (2013) suggestions, we can say that building an educational system that encourages young people to feel interest for learning cannot only be a responsibility of students and teachers. It requires a holistic perspective that incorporates all social and political agents that participate in the process of socialization and education of young people, both inside and outside school.

This article presents the results of the doctoral thesis "Learning trajectories across contexts. Two case studies on youth transitions inside and outside school" (Miño, 2017), which addressed the research problem described in this introductory section. The thesis explored how young people aged 12 to 18 years old learn when they move across formal, informal and non-formal educational contexts. Its primary purpose was to describe and analyze youth' learning trajectories across the contexts in which they are involved, examining the relationships they establish with others, with themselves, with knowledge and with digital media.

In the next section, I bring together some of the main studies that have been conducted in the last years in the field of learning across contexts from a sociocultural approach. Next, I present the methodological perspective that has been used, emphasizing how ethnographic and participatory methods allowed understanding young people's experiences from their optics. In the results section, I bring back their voices to discuss: (i) the notion of learning trajectory across contexts in the digital age and (ii) youth' perspectives of secondary school as a node of a wide sociocultural network. Finally, in the discussion I question if understanding young people's learning trajectories across settings and time might help us to promote a more equal education for the $21^{\text {st }}$ century.

\section{Theoretical framework. Youth' learning trajectories in the digital age}

There are many studies that demonstrate that learning is not only a cognitive process, but also social, cultural and emotional (Gardner, 1998; Immordino \& Damasio, 2007; Lave \& Wenger, 1991; Vygotsky, 1978;). These dimensions make the study of learning complex, multidisciplinary and contextual, since each learner has a life story and each learning situation is affected by a huge amount of factors that would be impossible to control. In this vein, the contributions of Lave \& Wenger (1991) are still relevant to study which kind of encounters and social commitments among individuals afford opportunities to promote learning. According to the authors, learning is always situated and it involves participation in the social world. Therefore, we need to take into account the relationship between the learner, the world and the individuals with whom they relate.

Sociocultural studies value "learning that is embedded within meaningful practices and supportive relationships, and that recognizes diverse pathways and forms of knowledge and expertise" (Ito et al, 2013, p. 9). Through this approach, it is considered that individuals are not part of only one social context, but they are constantly navigating through contexts whose cultures have commonalities and divergences. This perspective is especially useful when it comes to research how young people learn through formal, non-formal and informal contexts. One relevant contribution in this regard is Barron's (2006) theory of learning ecologies, which addresses the interrelationships between individuals and the contexts where they learn and especially the 
diversity of contexts of which they are part. Bridget Barron claims that each social context "is comprised of a unique configuration of activities, material resources, relationships, and the interactions that emerge from them" (p. 195). Consequently, contexts cannot be studied only separately, but educational research has to stress the relationships that are produced when contexts converge.

An example of this convergence would be the relationship between student, family and school. According to Bernstein's (1988) study of school culture, the level of comprehension and acceptation of the finalities of the school by the families might influence the role of the students in school. For instance, if a family insists on the importance of attending school or they reject the school values, it can influence the way students conceive the activities proposed by their teachers. Therefore, family's attitude towards school might help students to engage or to have a role of separation, postponement, estrangement or alienation.

Bernstein's theory deepened precisely in the relationship between the two main contexts in which the majority of young people participate (home and school), as a small part of his complex analysis. Nevertheless, some contemporary researchers went beyond and studied the sociocultural network formed by formal, non-formal and informal contexts where young people learn. According to Erstad (2013), four relevant empirical approaches that studied youth' learning experiences across contexts and through different trajectories are:

- Studies on After-school Programs that want to involve young people in learning trajectories that are alternative or complementary to formal school-based learning (Cole, 2006).

- Studies on the Funds of Knowledge, which informed about everyday practices of young people and its impact in school (Gonzalez, Moll \& Amanti, 2005).

- Biographic and Ethnographic Studies that have been conducted through long periods of time, following specific students to understand the complexities of the learning processes in which they are involved (Thomson, 2008).

- Studies of User-generated Content Creation, which focused on the youth as active producers of content across contexts and their active roles in their learning trajectories (Lankshear \& Knobel, 2011).

These authors considered that it is not enough to understand how young people learn in school, but also in the playground, when they have dinner with their families, when they record themselves and upload a video on Youtube, when they play videogames or read a novel. Therefore, the authors stressed the relevance of accepting that school is only one of many contexts where young people learn in the digital and networked age. "Schools and schooling are no longer accepted as the exclusive sites for learning discipline-specific skills and knowledge" (Erstad \& Sefton-Green, 2013, p. 14).

One of the difficulties we encounter when doing research across time and settings is to follow a learning process that we define as fluid, mobile and multisited. According to Erstad \& Sefton-Green (2013) "we need to develop forms of analysis that can capture interaction -and especially that which might take place across the different dimensions of context in time and space" (p. 3). They also emphasize the necessity of going beyond an analysis of the dichotomy between youth experiences in and out-of-school to explore interactions, tensions and connections. For instance, some studies tried to understand how outside school educational environments might complement or support the school curriculum. Bell et al (2009) studied different families to see how young people participation trajectories on science-specific issues could be related with their school-based science education. Another example would be the Connected Learning study, which explored cases in which young people pursued a personal interest with their friends or family and linked it with academic achievement, career possibilities or civic engagement (Ito et al, 2013). 
Another focus of attention in the study of learning across contexts has been learner's identity. Arnseth \& Silseth (2013) used the term "learning selves" in order to deep into how individuals become specific kinds of learners. Through a dialogic approach, they consider that "a person's identity is not something given in advance of social interaction but is something dialogically constructed in and across participation trajectories and different timescales" (p. 30). They exemplify how young people use categories to define themselves and to create their identities. For example, the fact that a student has built a story of herself as a person who has always had difficulties at doing mathematic exercises influences the way she sees herself as a learner in Math classes.

Understanding better young people's learning experiences and identities implies doing research on how one person participates in different social contexts and connects her experiences through trajectories of participation. According to Ole Dreier (1999), when learners move across contexts, they might be constantly considering, evaluating and reviewing the meanings they build. But what happens when they find a contradiction? And how do they create connections between meanings, events, discourses or experiences? Erstad (2015) emphasizes that learning trajectories are also composed by discontinuities between activities and interests that might have educational implications for students. For example, there can be an opposition between students' interests and school learning, but at the same time the resources provided by the school might have an impact on their educational trajectories later on.

Another interesting point of Dreier's (1999) approach is that despite the fact that people participate in social contexts in diverse ways, they need to adapt to the rhythms of each social institution. However, some institutions try to impose a specific trajectory of participation to its members, while others are more flexible. If we transfer this idea to secondary school, we see how some pedagogical approaches consider that every learner should learn the same by doing identical activities and during the same amount of time, while others accept and promote learners' participation in different activities or projects, helping them to connect their knowledge and interests with new experiences.

Another dimension of the study of young people's learning experiences is their relationship with digital technologies. Being part of a digital and networked society implies that individuals have much more access to information and that digital devices are ingrained in their daily lives. At the same time, the use and presence of digital media in their lives have an impact in the whole society in terms of production, economy, politics, ecology and culture. As Selwyn (2012) puts it, we need to study the practices that take place in local and cultural contexts -related with language, religion or geography- but at the same time recognize the influences of a bigger political framework related with technology, power and control-.

In relation with the presence of digital technology in young people's lives, some studies have shown its impact in the ways they communicate, consume, create and interact. With no doubt, digital media can represent countless opportunities for young people to share, create and expand their horizons (Ito et al, 2013). One of the main reasons why some scholars such as Erstad \& Sefton-Green (2013) call them Net Generation is that youth presence in virtual spaces has grew up without precedents and it is changing their practices both inside and outside school in ways we are still starting to understand.

As a space, the Internet has become increasingly central as an alternative location for a broad set of practices that extend, complement or supplement everyday or learning practices in schools. It is, of course, the idea that persistent interaction with digital technologies has changed fundamental aspects of how young people create, interact 
with others and develop themselves that lies at the heart of the Net Generation hypothesis (Erstad \& Sefton-Green, 2013, p. 89).

We may not fall again into binary categories that consider all young people digital natives and therefore tech-experts, but we need to consider that there is a "different kind of learning self who can act with authority across a series of domains and who is accustomed to collaboration, genuine challenge, experimentation, risk-taking, curiosity and expressivity" (Erstad \& Sefton-Green, 2013, p. 91). According to the authors, in the so-called participatory media culture (Jenkins, 2006), digital technology has blurred the distinction between production and consumption.

A matter that emerges from this discussion is to which extend the use of digital technology can contribute to create a more equal educational system or to grow inequities. The empirical research done by Barron (2006) and Ito et al (2013) show a lot of grey areas. On one hand, there is a clear divide between the use of digital media among youth from dominant and non-dominant social classes. We can see this divide not only in school -for example, in countries where students are segregated into state and private schools- but in other contexts out-of-school -such as extracurricular activities, family background and other social relationships-. On the other hand, digital technology expand the possibilities for young people to "(i) offer engaging formats for interactivity and self-expression, (ii) lower barriers to access for knowledge and information, (iii) provide social supports for learning through social media and online affinity groups, and (iv) link a broader and more diverse range of culture, knowledge, and expertise to educational opportunity" (Ito et al, 2013, p. 6).

This leaves us with a challenge that cannot be solved solely by the presence of digital technologies, but it requires understanding how they impact our society. This challenge is to transform the educational system so it can engage students with diverse opportunities, interests, knowledge and family support. In this vein, we need to reimagine the system and to propose changes that allow us to face the challenges of the $21^{\text {st }}$ century and rethink the industrial models on which our scholar institutions are based (Erstad, 2013; Sancho, 2001).

\section{Methods}

The doctoral thesis "Learning trajectories across contexts. Two case studies on youth transitions inside and outside school" was part of the Spanish national project "Living and learning with new literacies inside and outside school: contributions for reducing school dropout, exclusion and disaffection among youth". The project was implemented from 2011 to 2015 and its main purpose was to investigate youth' learning experiences in and outside school through a participatory ethnography. The methodological approach was designed to do research with young people (Hernández, 2011), conducting collaborative workshops with groups of students and using visual and creative strategies.

The project was carried out in five secondary schools from Catalonia by 11 university researchers and the participants of the study were 34 students in their last year of compulsory education (1516 years old). Some institutions selected the students while others recruited volunteers, but all the groups were formed by students who met and who did not meet the school's expectations. The main objective of the cases was to understand young people's learning trajectories across scholar and non-scholar contexts, in order to identify the connections and tensions they feel when they move across formal, non-formal and informal educational institutions. 
This article is based on two case studies. The first is one case of the national project called Els Alfacs. It was carried out with a group of 11 youth aged 16 to 18 years old and their Art teacher. Over 27 sessions in an extracurricular environment, the youth participated in discussions and workshops on interviewing, observing, taking field notes and video editing. Using the strategy of story telling (Harper, 2009), the group created 11 personal learning stories composed by maps, images, texts and videos. The specific focus of this case was to understand youth' learning practices out-of-school, in relation with their experience in school.

The second case study was not part of the national project and it was called Quatre Cantons. It took place in a secondary school that was defined as an "ordinary, open, diverse and inclusive secondary school, compromised with a useful education for the citizens of the $21^{\text {st }}$ century" 2 . This institution was chosen because its educative project was focused on the necessity to bridge youth experiences in and outside school. The participants were 11 youth in their first year of compulsory education (12-13 years old), their Spanish teacher and the school headmaster. I carried out 36 participatory observations, 3 focus groups and informal interviews with the youth. The finality of this case was to understand the school' learning culture from the youth' points of view, in relation with their experience out-of-school.

Table 1 presents the main characteristics of the case studies and the participants.

\begin{tabular}{|l|l|l|}
\hline & \multicolumn{1}{|c|}{ Case study Els Alfacs } & \multicolumn{1}{c|}{ Case study Quatre Cantons } \\
\hline $\begin{array}{l}\text { Characteristics } \\
\text { of the schools }\end{array}$ & $\begin{array}{l}\text { - Public secondary school. } \\
\text { - Semi-rural area. }\end{array}$ & $\begin{array}{l}\text { - Public secondary school. } \\
\text { - Urban area. }\end{array}$ \\
\hline $\begin{array}{l}\text { Characteristics } \\
\text { of the field } \\
\text { work }\end{array}$ & $\begin{array}{l}-27 \text { participatory sessions } \\
\text { of one hour in an } \\
\text { extracurricular environment. }\end{array}$ & $\begin{array}{l}-36 \text { observations of } 2-4 \text { hours } \\
\text { in a curricular environment. } \\
-3 \text { participatory sessions in an } \\
\text { extracurricular environment. }\end{array}$ \\
\hline $\begin{array}{l}\text { Characteristics } \\
\text { of the } \\
\text { participants }\end{array}$ & $\begin{array}{l}\text { years old (9 girls, } 2 \text { boys). } \\
\text { - Art teacher. }\end{array}$ & $\begin{array}{l}\text { - } 11 \text { youth aged } 16 \text { to } 18 \\
\text { - Spanish teacher. } 5 \text { boys). } \\
\text { - Headmaster. }\end{array}$ \\
\hline
\end{tabular}

Table 1. Characteristics of the case studies and the participants.

Source: The author.

Both case studies sought to understand young people's learning experiences across contexts through their perspectives, by accompanying them in the production of learning stories. The methodology was design to "make sense of social settings and social behaviors from inside, privileging the perspectives of the people involved in the situation that is the focus of the investigation" (Sikes, 2003, p. 13).

Creating learning stories answered to the difficulty of doing research on learning across settings and time. According to Vadeboncoeur, Kady-Rachid \& Moghatader (2015) and Vossoughi \& Gutiérrez (2015), it requires developing a multisited sensibility and using innovative methodologies that contemplate cultural and historical approaches to learning. This is the reason why the formal research was nourished by multisited ethnography (Falzon, 2009; Marcus, 1998); to go beyond the temporal and spatial limits that usually circumscribe educational research. It was also narrative,

\footnotetext{
${ }^{2}$ Fragment extracted from the web page of the school. 
considering that young people are storytellers whose stories have been individually and socially built (Clandinin \& Connelly, 1998).

With these methodological decisions, I wanted to contribute to the comprehension of the connections young people establish between moments, places and social contexts. Building learning stories is a collaborative strategy that allows following "people, connections, associations and relationships across space, because they are substantially continuous but spatially noncontiguous" (Falzon, 2009, p. 2).

The methods used throughout the research were: participatory observations, informal interviews, focus groups (Barbour \& Kitzinger, 1999) and visual participatory strategies (Harper, 2009). On the one hand, as a researcher I kept a field diary, transcribed the interviews and took photographs of the sessions. On the other hand, the youth created personal learning stories about their experiences inside and outside school by using strategies such as mapping, story telling and collaborative collage. In order to ensure the quality of the research design, every participatory session and focus group was recorded and I conducted informal interviews with teachers and students in both cases.

In order to analyze the transcriptions of the participatory sessions, the interviews, the focus groups and the learning stories written by the youth, I used micro and axial coding. Following the second generation of authors of Grounded Theory (Corbin \& Strauss, 2008), I identified and categorized the actions, interactions, relationships, meanings and emotions that young people related with their learning experiences in and out-of-school.

The first stage of the analysis -microcoding- consisted on codifying the data. Afterwards, the codes and quotations were organized into tables where categories and subcategories were formed. Reflexive memorandums were added in order to give account of the decisions taken during the analysis. The second stage -axial coding- was used to identify relationships between categories and reconstruct the dimensions of learning across contexts from the case studies. The dimensions explored through the analysis were: (i) learning experiences outside school, (ii) secondary school culture, (iii) youth engagement and (iv) use of digital media.

\section{Results}

In this section, the results from the case studies are organized in four parts that correspond with the dimensions of the analysis. The first part presents the learning stories told by the youth and the emerging concept of learning trajectory. Secondly, I introduce some of the tensions and connections that were present in the stories. In the third part, I collect some of the participants' contributions that explored the meanings of attending school and the notion of secondary school as a node of a wide sociocultural network. Finally, I make reference to the presence and impact of digital media in young people's learning trajectories.

\section{a. Learning stories across contexts and events}

I started this research by wondering how young people learned in and outside school. However, through the analysis I realized that their learning experiences are not separated, but constantly related. Taking into account the literature on the topic, I decided to move the research focus towards the relationships young people establish between the contexts where they learn. The analysis of their stories explored the intersection between their learning experiences at home, at class, through extracurricular activities, in their free time, when they travel, with their friends and through virtual environments. 
The participants begun by choosing activities through which they were learning. The activities they chose were related with Arts (photography, painting, drawing, composing, singing, theatre, Arts and crafts), Culture (travelling, reading and sharing an intercultural friendship), Digital Technology (Audiovisual production) and Sports (Twirling, Swimming, Rowing and Hokey). Through their narratives, they wrote, visually represented and spoke about the reasons why they engaged in those activities, the moments and people they considered significant, the social contexts through which they moved and the feelings that the activities provoked in them.

For example, Frida ${ }^{3}$ spoke about her passion for arts and crafts, which started at home when she was a child and she started to modify materials she had at her disposal to create all kind of crafts. She used to think that she did it to keep herself busy, but with time she realized that it was something comforting that made her feel relaxed and proud of herself. It also helped her to communicate, to express her worries and to represent serious issues, such as woman abuse. She realized that there was a learning process behind her creations, since she had been improving her techniques, paying more attention to the materials and the presentation of her creations and learning how to be patient, one of the most important attitudes in a society that change at a frenetic pace.

Analyzing Frida's learning story made me realize that the stories told by the youth had some aspects in common. First, they all made reference to significant events and people who provoked a meaningful change in their learning identities. Secondly, they referred to diverse contexts through with they moved when they learned. Thirdly, they mentioned connections or tensions between those contexts. I decided to use the metaphor of learning trajectory because it was useful to capture the idea that learning is a process of constantly connecting ideas, contexts, people and events, allowing learners to broaden their knowledge horizons.

For instance, Frida referred to five different social contexts or relationships when she explained how did she learn to make crafts: home, primary school, secondary school, virtual environments and friendship. Her home was the most highlighted context, since her father was a sculptor and her uncle was a professor at the faculty of Fine Arts. As she explained, they taught her many techniques and skills related with art.

When it comes to arts and crafts, I would talk about my father, who is a sculpture, and one of my uncles, who is a professor at the faculty of Fine Arts at the University of Valencia. They both taught me many techniques to improve my crafts. Thanks to them I have learnt to finish the crafts well, polished and with a good presentation, taking care of the most minimum detail and being accurate (Case Els Alfacs, February 12th, 2013, video recording of Frida's learning story).

She also mentioned primary and secondary school, since she loved attending Art classes and showing her crafts to her classmates. She specially referred to a teacher who invited her to participate in a contest, where she presented a lamp she did with recycled material, helped by her uncle. She mentioned virtual environments because she used to search for inspiration at the Internet. Finally, she spoke about her friends, who supported her and received her crafts as presents.

Frida's story is just one example of how young people build their learning identities (Arnseth \& Silseth, 2013) by moving constantly across contexts, even when these transitions are unconscious. When I analyzed the 22 stories, I realized that every social context mentioned by the youth gave them opportunities and tools that were necessary to do an activity. No matter if they spoke about photography, travelling, doing sports or singing, they all needed some support and material. Family was the institution they mentioned the most, but the participants who did not refer to their family

\footnotetext{
${ }^{3}$ The names have been changed to maintain the anonymity of the participants, as it was indicated in the written consent that was signed by the youth and their families.
} 
talked about other social relationships or contexts that compensated them.

\section{b. Tensions and connections across contexts}

Leander, Philips and Headrick (2010) conceive learning as a mobile social practice. That is to say that people are constantly moving across social systems in which they learn. From this analytical framework, it is key to understand how young people connect one environment with another in their daily life and how learning opportunities are organized and created through trajectories that connect multiple locations and events. In Frida's case, it was clear that she constantly created relationships of continuity between home, school and virtual environments. Her learning experiences at home were complemented by the activities her teachers proposed and at the same time, she would search at the Internet for some tutorials to look for inspiration. Therefore one kind of relationship between contexts that appeared in their stories was continuity and complementarity. In this case, there was harmony between contexts and the learner was willing to connect them.

However, young people do not always feel continuity between contexts. When Vivian talked about taking photographs out-of-school, she expressed that it had nothing to do with taking pictures with a school purpose. Out of school, photography was an opportunity for her to express, capture moments, reflect about her live and generate visual metaphors to explain her feelings. Therefore, when she took pictures outside school, she did not have a specific thematic or deadline, but inspiration came all of a sudden. Contrarily, in a subject where the teacher assigned her a project based on photography, she was frustrated because she had to decide the topic before taking the pictures.

Her story revealed a tension between activities in school and out-of-school that were interrelated. It also unveiled that when teachers assign a school activity that is related with the youth' interests, the students will not necessarily connect them and it could even be frustrating for them. The reason that might be behind this tension might be the learning and teaching culture of the school, when it imposes rules that are not usually imposed out-of-school.

Nevertheless, even when there was a tension between learning about a topic in and out-of-school, the activities were somehow connected. For instance, Robert considered that he learned better about the Second World War by playing videogames than listening to the teacher, but at the same time, he was indicating a connection between what he learned by playing videogames and attending school.

Videogames say a lot of things about the Second World War. I retain it more when a videogame tells me how the war started that when a teacher says it (Case Quatre Cantons, May 22nd, 2013, Robert's intervention in a focus group).

Another participant that expressed a tension across contexts was David, who used to reject curricular knowledge and activities. He considered that he could learn more by searching at the Internet that listening to the teachers, so he spent his time at class looking at web pages. He decided to learn informatics and video editing by watching tutorials online and by trial and error. In some years, he became an IT expert in school, helping every teacher and student to solve problems and do projects that required digital skills. He also used to participate in extracurricular activities that were related with digital technologies, such as organizing a karaoke or recording and editing videos of cultural events. David story is an exemplification of how learning trajectories are formed by entangled relationships of connections and tensions between contexts and situations. 


\section{c. School as a node of a wider sociocultural network}

As learning stories show, school is only one of the many contexts where young people learn. According to Erstad (2015), "learning activities as experienced by young people today are much more interconnected and expanded across different settings than ever before" (p. 20). However, schools still have a great presence in their lives and even when they reject school activities, they can find alternative ways to engage and learn in school. For this reason, I look at the school as one of the nodes of the sociocultural network of contexts where young people learn.

One of the aspects I highlight from the analysis is that attending school does not mean the same for all youth. For some students, going to the school was as meaningful as it was for their family and teachers, whereas for others, it was meaningful inasmuch as it represented a chance to meet certain teachers and classmates or to do a specific activity. Conversely, for other students, attending school did not make much sense and they attended school every day because it was mandatory.

Maybe you won't be interested in some subjects now, but in the future if you want to do something related with Science, then you will need Math. And it is basic that they teach you how to add. If you want to have your own ideas, first you need to know what you are talking about; and it is something you learn here and not outside (Case Els Alfacs, October 23rd, 2013, Frida's intervention in a focus group).

I come here basically because I have to come here. I learn more outside school than inside. Here they teach me about subjects and all this, and maybe I won't learn about this stuff out-of-school (...) [but] I find more interesting -it will help me more to live-, what I learn outside school and small details that you cannot learn here (Case Els Alfacs, October 23rd, 2013, Simone's intervention in a focus group).

Furthermore, only some youth considered that they connected their daily life activities -for example, travelling, shopping or making decisions- with the subjects they were supposed to learn about at school -such as History, Arithmetic or Languages. While all the participants attributed to secondary school the function of teaching, not all of them found a relationship with their necessities in other contexts.

Through the case study Quatre Cantons I could see how the school played a key role to make the students experience meaningful. For instance, the teachers created a curricular space that was based on projects with the purpose of connecting school activities and youth' knowledge. It was called Commissions and the students had to chose among different projects related with Cinema, Theatre, Arts, Agriculture, Journalism, Science or Digital Technologies. Many youth described this curricular space as a context where the school connected with their interests and knowledge. I could observe this in Mouse Commission, where some students created a comic using Photoshop, while others published an entry in the school Blog and others created videotutorial to use the school's digital apps. Through the Commissions, the teachers tried that students contributed to the school with their knowledge, making them feeling valuable.

\section{d. Learning (with) digital media}

According to Leander, Philips \& Headrick (2010), researching learning today means to acknowledge how people, media and social phenomena move across locations, how they connect their global and local lives, how new spaces are being generated, and how speed and rhythms of social practices are changing. All these aspects were present in the learning stories told by the participants. For example, young people who used to travel or had friends with different cultural backgrounds spoke about broadening their horizons of comprehension and about how reality is much wider than what 
they see in the countries where they live. In the era of information and globalization, youth' realities expand further away from their home and neighborhoods.

Every day I learn more or less the same, but when I travel, it feels like I broad my horizons of knowledge (...). The experiences have been emotional... and physical... and cultural... There is a huge difference between how do we live here and in other parts of the world. For example, I would highlight the role of woman, the way they dress, their roles in society... (Case Els Alfacs, February 26th, 2013, video recording of Carles' learning story).

One of the impacts of living in the digital and networked era according to the youth' learning stories is that their realities expand beyond their local contexts. In Carles' case, he travelled with his family, but other youth migrated from one country to another. In all cases, they had access to information about what was going on in other countries and consequently, their horizons expanded much further away than they used to twenty years ago.

Another significant aspect related with learning in the digital age was their participation in virtual environments and communities, since the logics governing face-to-face environments were different from the ones of the virtual spaces. For instance, David talked about how he used to learn to edit videos by navigating through the Internet, watching tutorials, reading pieces of advice and uploading his productions to receive feedback from others. After that, when he went to school and he was expected to sit down and listen to the teacher, he rejected those practices and went back to navigating through the Internet. This might be related with the tension between school and out-ofschool teaching and learning cultures that was mentioned above. Nevertheless, as Thomas \& Brown (2012) show, many educators and educational institutions are already transforming their teaching and learning cultures into participatory and interest-based cultures. As I could see in the case study Quatre Cantons, teachers are able to teach academic content and promote participation among students at the same time, using digital technologies to connect with realities that exist beyond the class.

\section{Discussion}

This article addressed young people's participation in different activities and social contexts and the trajectories they form when they learn across settings and time. When we pay attention to the ways young people learn, interact, build knowledge and share it with others we see the importance of rethinking the educative system so it can pay attention to the students' experiences and knowledge. In this way we could be able to engage them, stimulate their learning and help them to develop as citizens able to live, cohabit and work in the contemporary world.

Following this idea, in this last section I highlight some of the results that could help to consolidate a more inclusive and holistic educative system:

- Young people's stories evidence that learning experiences across social contexts are constantly interrelated. However, these relations do not always imply a connection, continuity or complementarity. In some cases, the youth might feel a tension between their families' priorities and their teachers' proposals, or between the ways they use technology at home and at school. In the same vein, young people can find in one context the opportunities or tools that they do not find in another. The contexts where young people learn need to be understood as a network and not only as isolated environments.

- In relation with secondary school, there is a growing tendency to considerate young people's realities beyond the class. In both case studies, some teachers tried to facilitate that students established connections between what they knew and what teachers wanted 
them to learn. This pedagogical approach highlights the importance of establishing connections across subjects, working through projects and globalized proposals. Furthermore, both teachers and students emphasized the importance of creating pedagogical relationships of mutual recognition, built on respect, reliance and appreciation of the other's knowledge.

- Teacher education needs to respond to these new tendencies, exploring ways to connect school activities with the students' realities and addressing not only academic knowledge, but also knowledge for living. We are now more aware than ever that social and emotional learning components need to be taken into consideration, but it is still a challenge to be addressed in secondary schools.

- Living on a digital and networked age implies an increase of young people's mobilities between countries, which have an impact on their learning identities and trajectories. Many young people move across countries with their families because they are searching for better life conditions, while others travel because they want to understand other contexts and cultures. The reasons they have to move in these cases are quite different and we need to study further the implications of those differences in their learning trajectories. This is another aspect that might be taken into consideration in schools if we want to build an inclusive educative system.

Finally, some of the limitations of the study are highlighted, acknowledging that they can be opportunities to keep doing research in this field:

- In relation to the sample, the participants were young people who were engaged in the educational system. They went to secondary school and wanted to participate in a research about their own learning experiences. I would suggest conducting participatory research about learning across contexts with young people who are not engaged in high school, to take their perspectives into account.

- Secondly, due to the limited time of the study, it was difficult to follow up youth learning trajectories, finding connections between experiences that took place in different moments and spaces. The connections and tensions that are mentioned in this article were told by the youth through storytelling, but it was not possible to see the longitudinal effects of the learning experiences they were living at that moment.

- Thirdly, it would also have been enlightening to trace the learning experiences of young people who have lived similar live conditions, such as migrating from one country to another or living in a children's center.

The results and the limitations of this doctoral thesis are possibilities to do further research on youth learning trajectories, digital media and social inclusion. In this vein, I end up by mentioning two directions that could be followed: (i) exploring how in and outside school educators are trying to foster diverse learning trajectories across educational environments, and (ii) doing research on meaningful learning experiences promoted in schools that consider youth' realities beyond school. 


\section{Acknowledgments}

The author acknowledges the ESBRINA Research group. Subjectivities, Visualities and Contemporary learning environments (2014SGR 00632) and the Spanish Ministry of Economy and Competiveness for financing the study "Living and learning with new literacies inside and outside school: contributions for reducing school drop-out, exclusion and disaffection among youth" (EDU2011-24122).

\section{References}

Arnseth, H.C., \& Silseth, K. (2013). Tracing Learning Identity Across Sites: Tensions, Connections and Transformations in and Between Everyday and Institutional Practices. In O. Erstad \& J. Sefton-Green (Eds.) Identity, community, and learning lives in the digital age (pp. 23-38). New York: Cambridge.

Bailón, M., Carballo, M., Cobo, C., Magnone, S., Marconi, C., MATEU, M., \& Susunday, H. (2015). How can Plan Ceibal Land into the Age of Big Data? In Data Analytics 2015: The Fourth International Conference on Data Analytics. IARIA. Retrieved from: http://blogs.ceibal.edu.uy/tecnologia/wpcontent/uploads/2016/04/data analytics 201572060119 G.pdf

Banks, J. A., Au, K. H., Ball, A. F., Bell, P., Gordon, E. W., Gutiérrez, K., Heath, S.B., Lee, C.D., Lee, Y., Mahiri, J., Nasir, N.S., Valdes, G., \& Zhou, M. (2007). Learning in and out of school in diverse environments. life-long, life-wide, life-deep. Seattle: The LIFE Center \& Center for Multicultural Education, University of Washington. Retrieved from: http://life-slc.org/docs/Banks etal-LIFE-Diversity-Report.pdf

Barbour, R., \& Kitzinger, J. (1999). Developing Focus Group Research: Politics, Theory and Practice. London, UK: Sage.

Barron, B. (2006). Interest and Self-Sustained Learning as Catalysts of Development: A Learning Ecology Perspective. Human Development, 49, 193-224. Retrieved from: http://life-slc.org/docs/barron-selfsustainedlearning.pdf

Berliner, D. (2013). Effects of Inequality and Poverty vs. Teachers and Schooling on America's Youth. Teacher College Record, 115(12). Retrieved from: https://pdfs.semanticscholar.org/9d17/9d15b47fca610e903bcef00f42141629aa6a.pdf

Bernstein, B. (1988). Clases, códigos y control II. Hacia una teoria de las transmisiones educativas. Madrid: Akal Universitaria.

Bell, P., Lewenstein, B., Shouse, A. W., \& Feder, M. A. (2009). Learning science in informal environments. People, places and pursuits. Washington DC: The National Academies Press.

Bland, D., \& Atweh, B. (2007). Students as researchers: engaging students' voices in PAR. Educational Action Research, 15(3), 227-249. Retrieved from: http://www.tandfonline.com/doi/abs/10.1080/09650790701514259

Clandinin, D. J., \& Connelly, F. M. (1998). Stories to live by: Narrative understandings of school reform. Curriculum inquiry, 28(2), 149-164. Retrieved from: http://www.tandfonline.com/doi/abs/10.1111/0362-6784.00082

Cole, M. (2006). The fifth dimension. An after-school program built on diversity. New York: Russell Sage Foundation.

Corbin, J., \& Strauss, A. (2008). Basis of qualitative research. California: Sage.

Dreier, O. (1999). Personal trajectories of participation across contexts of social practice. Outlines: Critical Social Studies, 1, 5-32. Retrieved from: https://tidsskrift.dk/index.php/outlines/article/view/3841

Erstad, O. (2013). Digital Learning Lives. Trajectories, Literacies, and Schooling. New Literacies and Digital Epistemologies. New York: Peter Lang. 
Erstad, O. (2015). Learning lives across educational boundaries. Continuity and discontinuity in learning trajectories. IJREE, 3(2), 9-22. Retrieved from: http://www.budrichjournals.de/index.php/IJREE/article/view/20886

Erstad, O., \& Sefton-Green, J. (2013). Identity, community, and learning lives in the digital age. New York, Cambridge.

European Commission (2016). European Semester: Thematic factsheet - Early school leavers - 2016. Retrieved from: https://ec.europa.eu/info/files/european-semester-thematic-factsheet-early-school-leavers2016 en

Falzon, M.A. (2009). Multi-sited Ethnography. Theory, praxis and locality in contemporary research. Burlington: Ashgate.

Gardner, H. (1995). Inteligencias múltiples. La teoría en la práctica. Barcelona: Paidós.

Gonzalez, N., Moll, L. C., \& Amanti, C. (2005). Funds of knowledge. Theorizing practices in households, communities, and classrooms. Mahwah, NJ: Lawrence Erlbaum.

Harper, K. (2009, December). New directions in participatory visual ethnography: possibilities for public anthropology. In 98th meeting of the American Anthropological Association (pp. 17-21).

Hernández, F. (2011). Investigar con los jóvenes: cuestiones temáticas, metodológicas, éticas y educativas. Barcelona: Repositorio digital de la Universidad de Barcelona. Retrieved from: http://hdl.handle.net/2445/17362

Hernández Hernández, F., Fendler, R., \& Sancho Gil, J. M. (2013). Rethinking Educational Ethnography: Researching on-line communities and interactions. Barcelona: University of Barcelona. Dipòsit Digital. Retrieved from: http://hdl.handle.net/2445/44009

Hine, C. (2004). Etnografía virtual. Barcelona: UOC. Nuevas Tecnologías y Sociedad.

Immordino, M.H., \& Damasio, A. (2007). We Feel, Therefore, We Learn: The Relevance of Affective and Social Neuroscience to Education. Mind, Brain and Education, 1 (1), 3-10. Retrieved from: http://onlinelibrary.wiley.com/doi/10.1111/j.1751-228X.2007.00004.x/abstract

Ito, M., Gutiérrez, G., Livingstone, S., Penuel, B., Rhodes, J., Salen, K., Schor, J., Sefton-Green, J., \& Watkins, S.G. (2013). Connected Learning: An Agenda for Research and Design. Digital Media and Learning Research Hub: Irvine. Retrieved from: https://dmlhub.net/publications/connected-learning-agendafor-research-and-design/

Jenkins, H. (2006). Convergence culture: Where old and new media collide. New York: New York University Press.

Kemmis, S., McTaggart, R., \& Nixon, R. (2013). The action research planner: Doing critical participatory action research. Geelong: Springer Science and Business Media.

Lankshear, C., \& Knobel, M. (2011). New literacies: Everyday Practices and Social Learning. United Kingdom: McGraw-Hill Education.

Lave, J., \& Wenger, E. (1991). Situated learning. Legitimate peripheral participation. Cambridge: Cambridge University Press.

Leander, K., Phillips, N., \& Headrick, K. (2010). The Changing Social Spaces of Learning: Mapping New Mobilities. Review of Research in Education. 34, 329-394. Retrieved from: http://journals.sagepub.com/doi/abs/10.3102/0091732X09358129?journalCode=rrea

Marcus, G.E. (1998). Ethnography through Thick \& Thin. New Jersey: Princeton.

Miño, R. (2017). Learning trajectories across contexts. Two case studies on youth transitions inside and outside secondary school (Doctoral dissertation). University of Barcelona: Barcelona.

Nind, M. (2014). What is inclusive research? London: Bloomsbury.

Nind, M. (2017). The practical wisdom of inclusive research. Qualitative Research, 17(3), 278-288. Retrieved from: http://journals.sagepub.com/doi/full/10.1177/1468794117708123

Sancho, J.M. (2001). Repensando el significado y metas de la educación en la sociedad de la información. In M. Area (Ed.), Educar en la sociedad de la información (pp. 37-79). Bilbao: Desclée de Brouwer. 
Selwyn, N. (2012). Ten suggestions for improving academic research in education and technology. Learning, Media and Technology, 37(3), 213-219. Retrieved from: http://www.tandfonline.com/doi/abs/10.1080/17439884.2012.680213

Selwyn, N. (2015). Data entry: towards the critical study of digital data and education. Learning, Media and Technology, 40(1), 64-82. Retrieved from: http://www.tandfonline.com/doi/abs/10.1080/17439884.2014.921628

Sikes, P. (2003). Introduction. In C. Pole, C., \& M. Morrison (Eds.). Ethnography for education. England: Open University Press. McGraw Hill Education.

Thomas, D., \& Brown, J. S. (2011). A new culture of learning: Cultivating the imagination for a world of constant change. Lexington, $\mathrm{KY}$ : CreateSpace.

Thomson, P. (2008). Doing visual research with children and Young people. Canada: Routledge.

Vadeboncoeur, J., \& Rahal, L. (2015). Mapping the Social Across Lived Experiences: Relational Geographies and After-School Time. Occasional Series, 30, 56-59. Retrieved from: https://www.bankstreet.edu/scholarly-initiatives/occasional-paper-series/30/out-of-schoolprograms/mapping-the-social-across-lived-experiences-relational-geographies-and-after-school-time/

Vadeboncoeur, J.A., Kady-Rachid, H., \& Moghtader, B. (2015). Learning In and Across Contexts: Reimagining Education. National Society for the Study of Education, 113(2), 339-358.

Vygotsky, L. S. (1978). Mind in society: The development of higher psychological processes. Cambridge: Harvard University Press.

Voussoughi, S., \& Gutiérrez, K. (2014). Studying Movement, Hybridity, and Change: Toward a Multi-sited Sensibility for Research on Learning Across Contexts and Borders. National Society for the Study of Education, 113(2), 603-632. Retrieved from: http://www.sesp.northwestern.edu/docs/publications/4140504435463b22673f60.pdf 